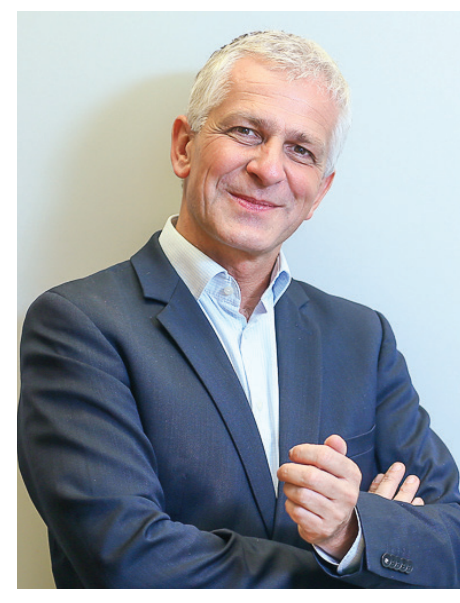

\title{
A Breath of Fresh Air
} at the End of Summer: And Some Thoughts About New Structures in Cancer Medicine

\section{Uma Lufada de Ar Fresco no Final do Verão: E Algumas Reflexões Sobre Novas Estruturas em Oncologia}

Dirk Arnold ${ }^{1}$

Coming back from our summer holidays, we find our desks and agendas overloaded with working pieces, to-do's and our agendas stuffed with meetings and appointments. However, the "fuelled batteries" and the fresher air will support our endeavours us to tackle those challenges - and may it be by chance or not, in this autumn's fresh air, respiratory medicine is a focus topic of this 3rd issue of Gazeta Médica.

In this, and amongst others, manuscripts from Prof. António Bugalho about Pneumologia in Portugal, and two up-to-date reports dealing with the most innovative treatments in lung cancers - from Prof. Bárbara Parente in a congress report and as an exclusive interview with Prof. Rolf Stahel from University of Zurich, about immunotherapy in lung cancers and other cancer types - enrich our knowledge.

As yet to see, cancer medicine is a second topic of this issue. Cancer is a specific challenge for all of us involved in medicine: One out of three Europeans will be diagnosed with a cancer disease during lifetime, and this has a massive impact on both, our private lives as well as our professional tasks: in which field of medicine we are practicing and taking care, many of our patients will have to deal with a cancer disease, demanding our support and consultation, even if the field of expertise is seen as „non-oncology" part of medicine.

Cancer is terrifying and concerning, and it generally is associated with fear and the image of suffering and hopelessness. At some points, for good reason. On the other side, there is plenty of good news about cancer: more and more patients can - and will - be cured. And even if cure cannot be reached: more and more patients live with their malignant disease under the conditions of a chronic disease, without numerous or severe symptoms and complaints. New diagnostical methods and new multidisciplinary treatment strategies, incorporating up-todate surgery, modern radiotherapy, as well as highly innovative (and efficacious) treatments are contributing to this success.

The complexity of cancer diagnostics and treatments are mirrored in some manuscripts in this Gazeta Médica, as yet mentioned above. Immuno- 
therapy is one oft he „big topics" of those days, but also other treatments change the landscape of therapeutic standards - to stay with pictures: in a breath-taking speed.

Just before the summer break, the Instituto CUF de Oncologia (ICO) was formally opened, representing a "state-of-the art" cancer centre, which is designed in the model of other European cancer care institutes: Given the complexity of the disease, its various clinical presentation (a nice saying of the Cancer Survivor's Council is: "cancer is not a disease, it is like 10 diseases...."), the numerous diagnostic and therapeutic modalities as well as all other aspects from patients (and their relatives), including co-morbidity and of course their personalities and psychological backgrounds it is obvious that this deserves a specific setting and organisation of best care.

Structures like the ICO facilitate this, by optimizing diagnostic and therapeutic algorithms, identifying and integrating the "best specialists", facilitating access to the most innovative treatments, and this across the whole network of its members and partners, accross Portugal. Cancer medicine is not limited to the most recent standards. It rather is "high innovation medicine", with standards very often changing within a very short time, also where access to clinical trials is a key factors. And as mentioned above, trials are of utmost importance, and as ICO also organizes access to cancer medicine trials - please see the História dos ensaios clínicos from
Dr. Vasco Salgado in this issue of the Gazeta Médica. And beyond innovative cancer treatments, the ICO also assembles disciplines which deal with the "whole picture" and needs of our cancer patients and their families - palliative care, nursing, psychosocial support, nutrition consultations, etc.

And of course, for information and education. Prof. Rolf Stahel, the former president of the European Society of Medical Oncology (ESMO, being Europe's 2nd largest medical society), visited us during the ICO opening, and I had the chance to discuss the concept of cancer centers and their various challenges in a European landscape and the Portuguese healthcare environment - and we can proudly say that our ICO concept, which started now within the Lisbon CUF units but will expand soon to other sites, is on the right track to facilitate this.

Coming back to our daily perspective: As yet stated, the increased rate of cured patients - and of those living with cancer - results in an increasing number in "cancer survivors". And in which field ever we are working, we all will be involved more and more into care of more-or-less-active-cancer patients. So, there is an urgent need to know more about, and structures like ICO will also take care for this. As well as the Gazeta Médica does, and in saying this, I would like to draw your attention to all of the other reports in this issue. And therefore, enjoy reading, and have a successful re-start, with a breath of fresh air. 